\title{
Interannual variations and regionality of Antarctic sea-ice-temperature associations
}

\author{
Andrew M. Carleton, Gareth John, Robert Welsch \\ Department of Geography and Earth System Science Center, The Pennsylvania State University, University Park, PA 16802, U.S.A.
}

\begin{abstract}
In the Antarctic, climate-scale anomalies of surface temperature $\left(T_{\mathrm{s}}\right)$ are associated with the atmospheric circulation and also sea-ice conditions. Negative (positive) anomalies of station $T_{\mathrm{s}}$ tend to accompany more (less) extensive sea ice in broadly similar longitudes. However, the relationship between temperature and sea-ice conditions during large interannual variations of the circulation has been little explored, as has its association over longer distances within Antarctica. This study examines the inter-associations between $T_{\mathrm{s}}$ at seven automatic weather stations in East Antarctica and the Ross Sea area, and sea-ice conditions in the sector $30^{\circ} \mathrm{E}$ eastward to $60^{\circ} \mathrm{W}$ for the three ice-growth seasons (March-October) of 1987-89. Strong between-year differences occur in the intercorrelations among station $T_{\mathrm{s}}$, sectoral ice extent and the relationship between the two climate variables, especially for 1988 and 1989. These differences are also expressed in the patterns of cold-air mesoscale cyclogenesis over sub-Antarctic latitudes. The study indicates that the $T_{\mathrm{s}}$-sea-ice link is modulated strongly in the presence of largescale interannual anomalies of the atmospheric circulation, including the El Niño-Southern Oscillation (ENSO).
\end{abstract}

\section{INTRODUCTION}

Surface temperature $\left(T_{\mathrm{s}}\right)$ is a climatic "integrator" of the radiation and energy budgets at the Earth's surface. In Antarctica the $T_{\mathrm{s}}$ field is closely linked to elevation, the strength of the near-surface katabatic winds, and also the circulation in the free atmosphere (Phillpot, 1991; Radok and Brown, 1996). Seasonal and interannual anomalies of Antarctic $T_{\mathrm{s}}$ are at least partly a function of the broadscale atmospheric circulation of higher southern latitudes (Rogers, 1983), including the El Niño-Southern Oscillation (ENSO; Smith and Stearns, 1993).

At stations in coastal Antarctica, the $T_{\mathrm{s}}$ tends to be negatively correlated with the "local" extent and duration of the sea ice on seasonal and longer time-scales (e.g. Jacka, 1990; Weatherly and others, 1991). Thus, the sea-ice record can be a proxy for temperature trends at regional and larger scales (King, 1994; Parkinson, 1995; Jacobs and Comiso, 1997). In the context of global climate change, reduced sea-ice extent probably exerts a positive feedback on global warming (Budd, 1991). Moreover, changes in the sea-ice extent influence precipitation in the Antarctic coastal zone by controlling the distance to the moisture source (Bromwich and Weaver, 1983; Giovinetto and others, 1990). They may also help determine the areas of, and time periods favorable for, the development of mesoscale cyclonic vortices ("mesocyclones") over higher latitudes (Fitch and Carleton, 1992; Carleton and Fitch, 1993). Mesocyclones are important in the climate of coastal Antarctica, particularly for snowfall (Streten, 1990; Rocky and Braaten, 1995), and also comprise a component of the atmospheric circumpolar trough near sea level (Turner and Thomas, 1994; Carleton and Song, 1997).

The negative association between the annual-averaged station $T_{\mathrm{s}}$ and Antarctic sea-ice extent is not always statistically significant (Jacka, 1990). This implies large interannual variations, and also changes in the relative importance of factors such as the synoptic atmospheric and upper ocean circulations (Ackley, 1981). Thus, to better evaluate the reasons behind recent Antarctic climate trends, one needs information on the interannual variability of the sea ice and its associations with temperature and the circulation (e.g. Harangozo, 1997).

This study determines the local and wider-area associations between the monthly $T_{\mathrm{s}}$ at several Antarctic automatic weather stations (AWSs) and the weekly sea-ice extent in the sector $30^{\circ} \mathrm{E}$ eastward to $60^{\circ} \mathrm{W}$, for the ice-growth seasons (March-October) of 1987-89. These years exhibited considerable interannual variations in ice and temperature conditions. Satellite-based inventories of mesocyclone activity for the South Pacific sector, developed for the two years exhibiting the most marked differences in the temperature-ice relationship (1988, 1989), illustrate the link between local $T_{\mathrm{s}}$ and the larger-scale atmospheric circulation.

\section{DATA AND ANALYSIS}

\subsection{AWS temperature data}

A number of AWSs have been operating in the Wilkes Land and Terre Adélie regions of East Antarctica (mostly Australian ones), and the Ross Sea area (mostly American ones), since the early to mid-1980s. Seven of these (Manuela, Martha-2, Whitlock, D-10, Law Dome, GF08 and GE03), plus Uranus Glacier on the Antarctic Peninsula, are used here because of their wide spatial distribution (Fig. 1). Also, their length of operation is sufficient to generate "long-term" temperature means from which individual month depar- 


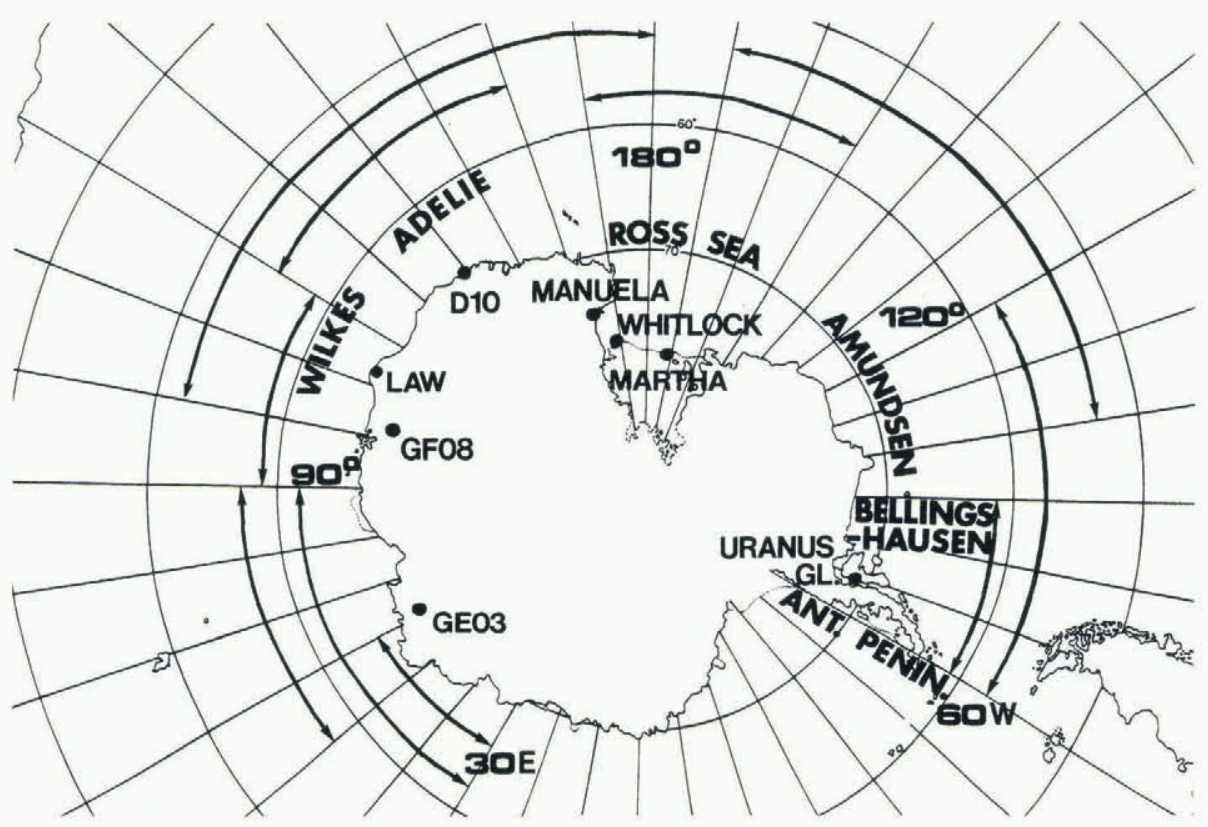

Fig. 1. Location map showing the seven East Antarctic AWSs, plus that at Uranus Glacier, and the ten longitude sectors for which sea-ice extent statistics were computed.

tures can be calculated. Aspects of the AWS climatology are given in Stearns and Wendler (1988) and Allison and others (1993).

Daily averages of $T_{\mathrm{s}}\left({ }^{\circ} \mathrm{C}\right)$ are computed from the 3 hourly data acquired by the U.S. AWSs in the Terre Adélie, Ross Sea and Bellingshausen Sea areas, and by the Australian AWSs in East Antarctica (Fig. 1), for the 1987-89 ice-growth seasons. For comparison with the sea-ice extent variations, a set of time-integrated temperature indices is developed for each AWS along the lines shown by Carleton and Fitch (1993) for the Ross Sea. Two indices noted to be particularly useful in that analysis are emphasized here. These are:

(1) the mean monthly temperature at each AWS for each of the three years (1987-89);

(2) the mean departure of the daily temperature from the "long-term" monthly mean at each AWS, in each year (1987-89).

The interrelationships of the temperature indices between AWSs for each year and also for the full 3 year period are determined by correlation, as are the AWS temperature associations with the sea-ice extent data.

\subsection{Sea-ice extent data}

The latitude location of the sea-ice edge comprises one possible measure of Antarctic sea-ice conditions (cf. Parkinson, 1994; Gloersen, 1995; Harangozo, 1997). It is determined for the 1 April-30 September period of each year (1987-89) using weekly analyses of the U.S. Navy-National Oceanic and Atmospheric Administration Joint Ice Center. These analyses utilize all available conventional and satellite data, and have been used in many studies of sea-ice-atmosphere interaction (e.g. Carleton, 1983; Jacka, 1990). The weekly iceedge latitude is obtained by averaging over $10^{\circ}$ longitude intervals. Averages of the sea-ice extent are then computed for ten sectors of variable size, comprising the entire $30^{\circ} \mathrm{E}-$ $60^{\circ} \mathrm{W}$ portion of the hemisphere (Fig. 1). The sectors, some of which partly overlap, are differentiated on the basis of their characteristic regional ice regimes documented in previous studies (e.g. Streten and Pike, 1980; Ackley, 1981; Cavalieri and Parkinson, 1981).

Standard bivariate correlation analysis (e.g. between ice extent and $T_{\mathrm{s}}$ ) and the computation of statistical significance require data that are independent (i.e. not temporally autocorrelated). To make negligible the persistence in the sea-ice series, which is of the order of 12 weeks for most regions (Carleton, 1989), we compute "first differences" by subtracting the ice-extent latitudes at the beginning of each month from those at the end of the month, for each longitude sector and for each month in the 3 year study period.

\section{RESULTS AND DISGUSSION}

\subsection{Antarctic sea-ice conditions, $1987-89$}

The zonally averaged $\left(30^{\circ} \mathrm{E}-60^{\circ} \mathrm{W}\right.$ sector $)$ weekly ice extents for the April-September periods of 1987-89 (not shown) reveal stronger interannual differences in the second half of the season. For example, the greatest ice extent in 1987 is recorded in early August, compared with early to mid-September in the other two years. Moreover, there is a difference in the zonally averaged latitude at maximum extent of about $0.5^{\circ}$ between the year of greatest ice (1987) and that with the least (1988). These variations are likely to be related, at least in part, to the shift from an ENSO "warm" to a "cold" event between 1987 and 1988 (Carleton, 1988; Gloersen, 1995; Simmonds and Jacka, 1995).

The inter-monthly and interannual differences in ice extent are most evident when considered by longitude (not shown), since the effects of differential ice growth and advection between sectors become apparent (e.g. Jacka, 1990; Parkinson, 1994). The 1989 season had strong (weak) equatorward ice-advance patterns in the sector from $150^{\circ} \mathrm{E}$ eastward to the Antarctic Peninsula $\left(100^{\circ} \mathrm{E}\right.$ eastward to $\left.140^{\circ} \mathrm{E}\right)$. Longitudinal differences in the ice-advance patterns are much less evident in both 1987 and 1988. Ice-growth in the sector $30-90^{\circ} \mathrm{E}$ is broadly comparable across all three years.

Intercorrelations of the monthly ice-extent changes 


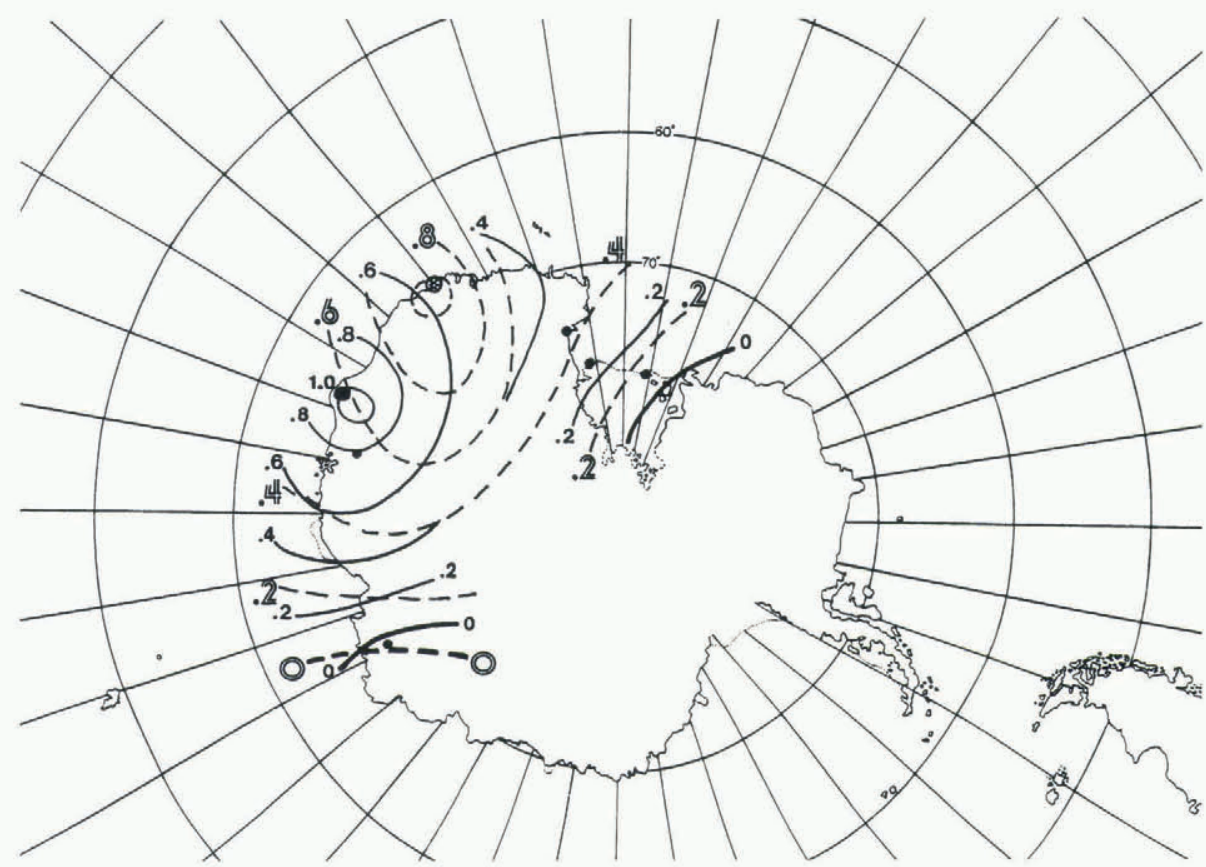

Fig. 2. Spatial patterns of the correlation between the mean temperature anomaly for the March-October period of 1987-89 at Law Dome (D-10) correlated with the other AWSs: solid isolines (dashed isolines).

among longitude sectors for each of the three years (198789) reveal that significant correlations are almost always positive, and they tend to occur more for adjacent and partly overlapping sectors than for those more distant. However, some long-range significant ice correlations were found, for example in 1987 between $50-90^{\circ} \mathrm{E}$ and 120 $60^{\circ} \mathrm{W}(r=0.790)$ and between $100^{\circ} \mathrm{E}-180^{\circ}$ and $90-60^{\circ} \mathrm{W}$ $(r=0.865)$. The number of significant ice intercorrelations varies over the three years, in 1988 being about half that of either 1987 or 1989. A similar interannual variation is evident in the intercorrelations of AWS temperatures (below).

\subsection{Antarctic AWS temperature associations, 1987-89}

Correlation matrices of the AWS monthly mean $T_{\mathrm{s}}$ and its anomalies give consistent results in terms of the sign and also number of significant inter-station correlations. All significant correlations are positive, confirming the more-orless zonal symmetry of temperature anomalies for Antarctica outside the Peninsula region (Rogers, 1983). There is also a spatial decay evident in the correlations, whereby stations closer to each other tend to be more highly correlated. Stations D-10 and Law Dome tend to be better correlated with the other stations used here than are GE03 or Uranus Glacier (Fig. 2). These correlation spatial patterns were used as a basis for regionalizing (grouping) stations for the icetemperature portion of the study, below. The four groups are Adélie/Wilkes (three stations: D-10, Law, GF08), the Ross Sea (three stations: Manuela, Martha and Whitlock), GE03 and Uranus Glacier.

There are considerable interannual variations in the number of significant intercorrelations of AWS $T_{\mathrm{s}}$, especially for 1988 (fewest: italicized values, Table 1) and 1989 (most: non-italicized values, Table 1), and therefore also in the spatial dependence of the temperature patterns. These may be related to ENSO. For example, Savage and others (1988) showed that the 1988 winter was unusually cold in Antarctica and followed the minimum in the Southern Oscillation Index (SOI) in 1987. This feature is consistent
Table 1. Intercorrelations of AWS monthly mean temperatures for ice-growth seasons 1988 and $1989^{*}$

1989

1988

Station Manuela Martha Whit- D-10 Uranus Law GF08 GE03 2 lock Glacier Dome

\begin{tabular}{llllll}
\hline Manuela & \multicolumn{5}{c}{0.538} \\
Martha 2 & 0.616 & & & \\
Whitlock & 0.830 & 0.769 & & & \\
D-10 & 0.631 & & 0.531 & 0.512 & \\
Uranus Glacier & & & & & \\
Law Dome & 0.503 & 0.708 & & 0.728 \\
GF08 & & 0.613 & 0.787 & \\
GE03 & & & & & \\
\end{tabular}

*Only $r$ values $> \pm 0.50$ are shown (i.e. $R^{2}>25 \%$ ).

with the composite pattern for such events shown by Smith and Stearns (1993).

\subsection{Sea-ice-temperature correlations, $1987-89$}

Correlation matrices (not shown) of station $T_{\mathrm{s}}$ (individual, grouped) and the sectoral sea-ice latitude monthly change reveal the following major features:

(1) the greatest number of significant correlations tends to occur in the sector from about $170^{\circ} \mathrm{E}$ to $60^{\circ} \mathrm{W}$, followed by the sector $30-90^{\circ} \mathrm{E}$;

(2) despite the generally positive spatial intercorrelations of AWS $T_{\mathrm{s}}$ and sectoral ice conditions when the three years are grouped together, both negative and positive correlations occur on an individual year basis. Here, positive coefficients imply either more ice (i.e. decreasing iceedge latitude) and lower temperatures, or less ice (i.e. increasing ice-edge latitude) and higher temperatures. 

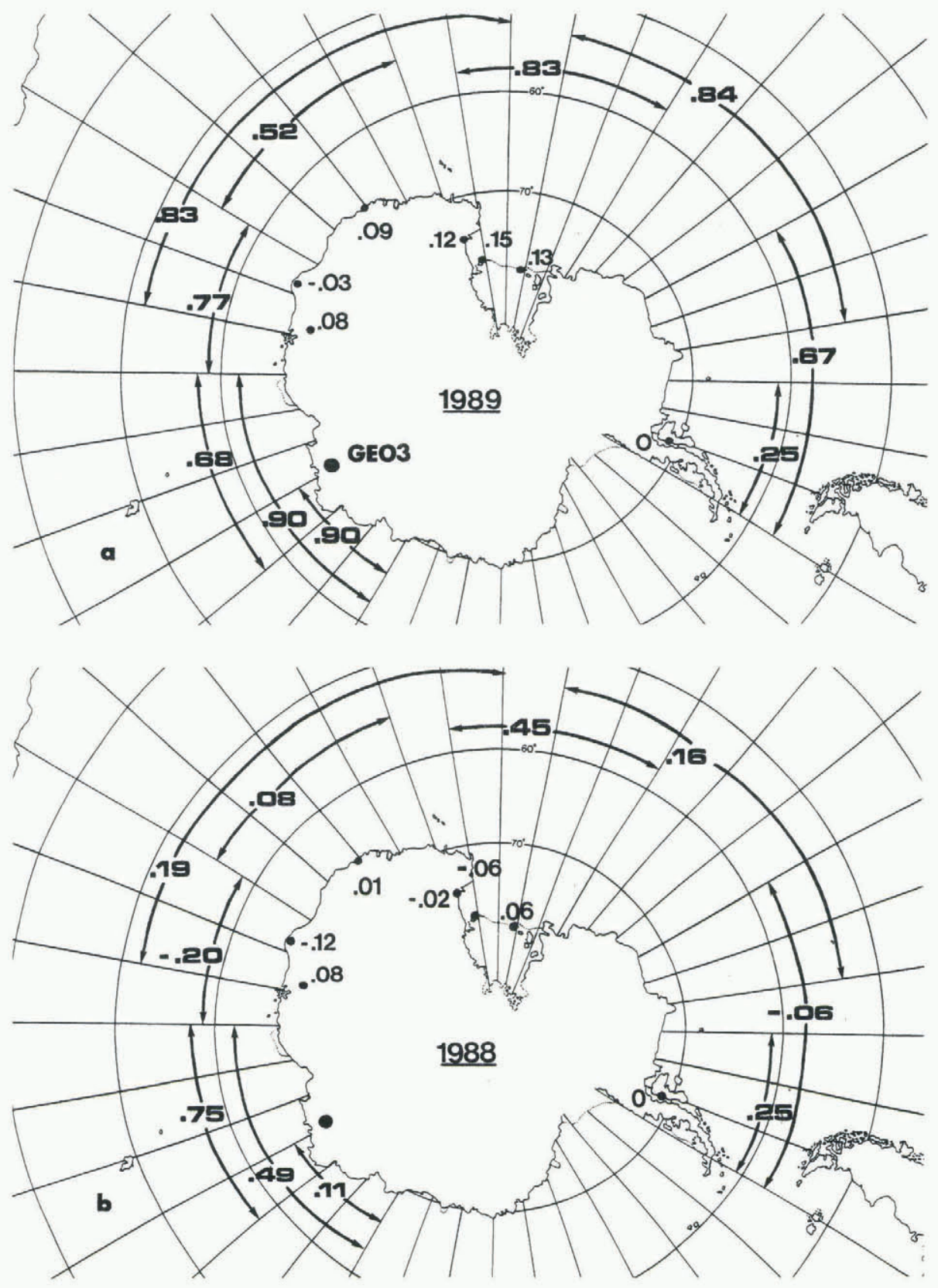

Fig. 3. Maps showing the intercorrelations of mean monthly temperatures at GE03 with the sea-ice latitude monthly change for each ice sector in 1989 ( a) and 1988 (b). Also shown are the correlations of $T_{\mathrm{s}}$ at GE03 and at the other AWSs for each season.

Negative coefficients imply the opposite in each case. Moreover, there is a consistent change over the three years in the relative frequencies of significant $T_{\mathrm{s}}$-iceextent correlations: from mostly negative in 1987 to mostly positive in 1989. This suggests changes in the relative importance of meridional flow for advecting the temperature anomalies into the sea-ice zone (Harangozo, 1997), which need to be studied further. This circulation feature may also be related to the SOI variations occurring during the 1987-89 period;

(3) the lack of consistency in the $T_{\mathrm{s}}$-sea-ice correlations between years is especially apparent for 1988 and 1989. For example, at station GE03 correlations are weak and longitudinally restricted (strong and widespread) in 1988 (1989), even though the correlation of $T_{\mathrm{s}}$ at GE03 with other AWSs is negligible in both years (Fig. 3a and b). These results confirm the reduced spatial consistency of both the AWS $T_{\mathrm{s}}$ and sea-ice conditions in 1988.

The role of $T_{\mathrm{s}}$ in influencing the strong differences in sea-ice extent occurring between the Ross and Amundsen/ Bellingshausen Seas for the 1988 and 1989 seasons is quantified through a measure of the longitudinal gradient of AWS temperature across the Ross Ice Shelf. This is a key site for katabatic outflows and their involvement in mesoscale cyclogenesis (e.g. Bromwich, 1991; Carrasco and Bromwich, 1994). Here, the daily $T_{\mathrm{s}}$ departure data for Manuela are subtracted from those at Martha-2 for each ice-growth season. Thus, positive (negative) differences in the index are associated with northerly (southerly) "thermal" wind in the boundary layer for this region. Figure $4 \mathrm{a}$ and b show that, for much of the ice-growth season of 1988 (1989), mild northerly (cold southerly) "thermal" winds predominated in the central and western Ross Sea. These accompanied the smaller (greater) increases in ice extent in those longitudes during the 1988 (1989) season, and are consistent with a larger-scale circulation pattern of a weakened (strengthened) Amundsen Sea "mean" low in 1988 (1989) (Carleton and Fitch, 1993, fig. 8). The latter comprises part of the ENSO signal in the Antarctic (Cullather and others, 1996). 

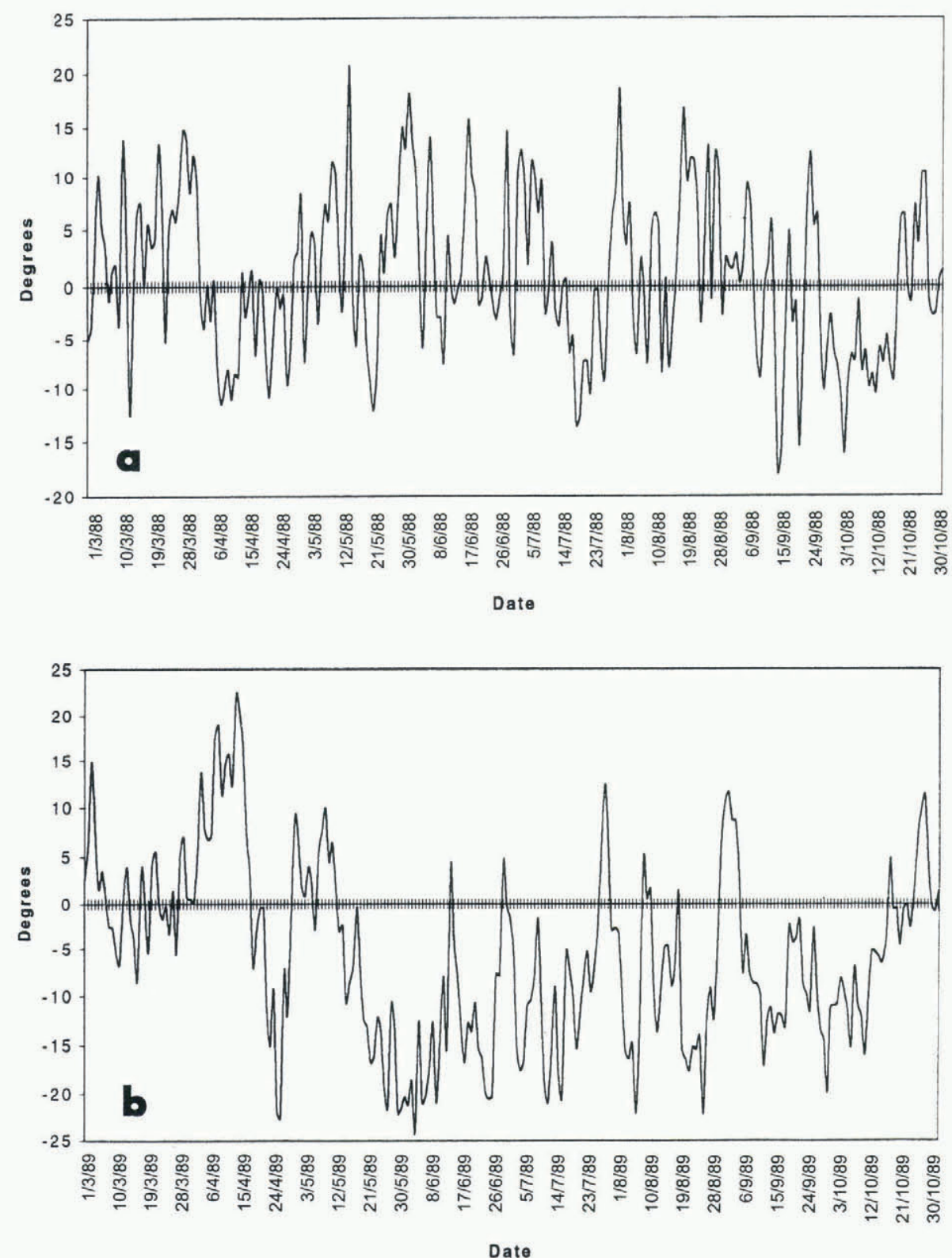

Fig. 4. Time plots of the mean daily temperature departures between Martha-2 and Manuela (cf. Fig. 1) for ice-growth seasons 1988 ( a) and 1989 ( b). Note the large between-year differences for the period May-August.

These differences in $T_{\mathrm{s}}$, ice conditions and atmospheric circulation are also reflected in the considerably greater frequencies of cold-air mesocyclones observed in longitudes of the eastern Ross Sea and Amundsen Sea in 1989 contrasted with 1988 (see Carleton and Fitch, 1993, figs 6 and 7).

\section{SUMMARY AND CONCLUSIONS}

A statistical analysis of the relationship between near-coastal $T_{\mathrm{s}}$ and Antarctic sea-ice extent for the $30^{\circ} \mathrm{E}-60^{\circ} \mathrm{W}$ sector has been undertaken individually for three ice-growth seasons characterized by large interannual variations of atmospheric circulation (1987-89). While a temperature-sea-ice relationship that involves greater (reduced) ice extent when temperatures decrease (increase) is evident both locally and sometimes over long distances, there are strong interannual changes in the magnitude, spatial homogeneity and even sign of the association. These results likely emphasize the variable role of the atmospheric circulation for advecting temperature anomalies within the sea-ice zone, and their larger-scale teleconnection with ENSO. They imply the need to examine the temperature-ice relationship for additional years having large variations of Antarctic circulation climate.

\section{ACKNOWLEDGEMENTS}

This research was supported by U.S. National Science Foundation Office of Polar Programs (OPP) grants 88-16912 and 92-19446. We are grateful to I. Allison and C. Stearns for supplying the data from the Australian and U.S. AWSs, respectively.

\section{REFERENCES}

Ackley, S. F. 1981. A review of sea-ice weather relationships in the Southern Hemisphere. International Association of Hydrological Sciences Publication 131 (Symposium at Canberra 1979 - Sea Level, Ice and Climatic Change), 127-159. Allison, I., G. Wendler and U. Radok. 1993. A climatology of the East Antarctic ice sheet $\left(100^{\circ} \mathrm{E}\right.$ to $\left.140^{\circ} \mathrm{E}\right)$ derived from automatic weather stations. J. Geophys. Res., 98(D5), 8815-8823. 
Bromwich, D. H. 1991. Mesoscale cyclogenesis over the southwestern Ross Sea linked to strong katabatic winds. Mon. Weather Rev., 119 (7), 1736-1752

Bromwich, D. H. and C.J. Weaver. 1983. Latitudinal displacement from main moisture source controls $\delta^{18} \mathrm{O}$ of snow in coastal Antarctica. Nature, 301 (5896), 145-147.

Budd, W. F. 1991. Antarctica and global change. Climatic Change, 18(2-3), 271-299.

Carleton, A. M. 1983. Variations in Antarctic sea ice conditions and relationships with Southern Hemisphere cyclonic activity, winters 1973-77. Arch. Meteorol. Geophys. Bioklimatol., Ser. B, 32(1), 1-22.

Carleton, A. M. 1988. Sea-ice atmosphere signal of the Southern Oscillation in the Weddell Sea, Antarctica. F. Climate, 1 (2), 379-388.

Carleton, A. M. 1989. Antarctic sea-ice relationships with indices of the atmospheric circulation of the Southern Hemisphere. Climate Dyn., 3(4), 207-220.

Carleton, A. M. and M. J. Fitch. 1993. Synoptic aspects of Antarctic mesocyclones. 7. Geophys. Res., 98(D7), 12,997-13,018.

Carleton, A. M. and Y. Song. 1997. Synoptic climatology, and intrahemispheric associations, of cold air mesocyclones in the Australasian sector. f. Geophys. Res., 102 (D12), 13,873-13,887.

Carrasco, J. F. and D. H. Bromwich. 1994. Climatological aspects of mesoscale cyclogenesis over the Ross Sea and Ross Ice Shelf regions of Antarctica. Mon. Weather Rev., 122(11), 2405-2425.

Cavalieri, D. J. and C. L. Parkinson. 1981. Large-scale variations in observed Antarctic sea ice extent and associated atmospheric circulation. Mon. Weather Rev., 109(11), 2323-2336.

Cullather, R. I., D. H. Bromwich and M. L. van Woert. 1996. Interannual variations in Antarctic precipitation related to El-Niño-Southern Oscillation. 7. Geophys. Res., 101 (D14), 19,109-19,118.

Fitch, M. and A. M. Carleton. 1992. Antarctic mesocyclone regimes from satellite and conventional data. Tellus, 44A (2), 180-196.

Giovinetto, M. B., N. M. Waters and C. R. Bentley. 1990. Dependence of Antarctic surface mass balance on temperature, elevation, and distance to open ocean. 7. Geophys. Res., 95(D4), 3517-3531.

Gloersen, P. 1995. Modulation of hemispheric sea-ice cover by ENSO events. Nature, $373(6514), 503-506$.

Harangozo, S. A. 1997. Atmospheric meridional circulation impacts on contrasting winter sea ice extent in two years in the Pacific sector of the Southern Ocean. Tellus, 49A(3), 388-400.

Jacka, T. H. 1990. Antarctic and Southern Ocean sea-ice and climate trends. Ann. Glaciol., 14, 127-130.

Jacobs, S. S. and J. C. Comiso. 1997. Climate variability in the Amundsen and Bellingshausen Seas. 7. Climate, 10(4), 697-709.
King, J. C. 1994. Recent climate variability in the vicinity of the Antarctic Peninsula. Int. J. Climatol., 14(4), 357-369.

Parkinson, C. L. 1994. Spatial patterns in the length of the sea ice season in the Southern Ocean, 1979-1986. J. Geophys. Res., 99(C8), 16,327-16,339.

Parkinson, C. L. 1995. Recent sea-ice advances in Baffin Bay/Davis Strait and retreats in the Bellingshausen Sea. Ann. Glaciol., 21, 348-352.

Phillpot, H. H. R. 1991. The derivation of $500 \mathrm{hPa}$ contour heights from automatic weather station surface observations in the Antarctic continental interior. Aust. Meteorol. Mag., 39, 79-86.

Radok, U. and T.J. Brown. 1996. Antarctic $500 \mathrm{hPa}$ heights and surface temperatures. Aust. Meteorol. Mag., 45, 55-58.

Rocky, C. C. and D. A. Braaten. 1995. Characterization of polar cyclonic activity and relationship to observed snowfall events at McMurdo Station, Antarctica. In Fourth AMS Conference on Polar Meteorology and Oceanography, January, 1995, Dallas, Texas. Proceedings. Boston, MA, American Meteorological Society, 244-245.

Rogers, J. C. 1983. Spatial variability of Antarctic temperature anomalies and their association with the Southern Hemisphere atmospheric circulation. Ann. Assoc. Am. Geogr., 73 (4), 502-518.

Savage, M. L., C. R. Stearns and G. A. Weidner. 1988. The Southern Oscillation in Antarctica. In 2nd Conference on Polar Meteorology and Oceanography, 29-31 March 1989, Madison, Wisconsin. Boston, MA, American Meteorological Society, 141-144. (Preprint.)

Simmonds, I. and T. H. Jacka. 1995. Relationships between the interannual variability of Antarctic sea ice and the Southern Oscillation. 7. Climate, $8(3), 637-647$.

Smith, S. R. and C. R. Stearns. 1993. Antarctic pressure and temperature anomalies surrounding the minimum in the Southern Oscillation index. 7. Geophys. Res., 98(D7), 13,071-13,083.

Stearns, C. and G. Wendler. 1988. Research results from Antarctic automatic weather stations. Rev. Geophys., 26(1), 45-61.

Streten, N. A. 1990. A review of the climate of Mawson: a representative strong wind site in East Antarctica. Antarct. Sci., 2(1), $79-89$.

Streten, N. A. and D. J. Pike. 1980. Characteristics of the broadscale Antarctic sea ice extent and the associated atmospheric circulation: 1972-1977. Arch. Meteorol. Geophys. Bioklimatol., Ser. A, 29 (3), 279-299.

Turner, J. and J. P. Thomas. 1994. Summer-season mesoscale cyclones in the Bellingshausen-Weddell region of the Antarctic and links with the synoptic-scale environment. Int. J. Climatol., 14(8), 871-894.

Weatherly, J.W., J. E. Walsh and H.J. Zwally. 1991. Antarctic sea ice variations and seasonal air temperature relationships. J. Geophys. Res., 96(C8), $15,119-15,130$ 